\title{
The comparative analysis of attack and defense ability for semi-finals of EURO 2012
}

\author{
Ke-lian $\mathrm{GAO}^{1, \mathrm{a}}$ \\ Department of Physical Education, Yulin College, Yulin 719000, China \\ a916490618@qq.com
}

Keywords: European Cup; Attack and defense; Statistical analysis

\begin{abstract}
The paper used literature, logical analysis, video clip playback and mathematical statistics, in 2012 the European Cup finals four teams enter the semi-finals of the German team, Portugal, Italy and Spain's offensive and defensive Comparative analysis of the situation. The results show that: in terms of passing the ball, the Spanish team in terms of the total number of passes, the threat of the ball and dominated possession rate; the team scoring the most positive goal in the penalty area; the second half than the first half the number of the number of goals scored; Road penetration and winger field goal is still the preferred way to attack the teams; fierce tackling and defensive tactical foul has become the team's overall tactics indispensable aspect.

After the 2012 European Cup has ended, the loudest voices won the Spanish team won the World Cup in 2010 and successfully defended the European Cup final to win the title - Delaunay Cup. The current European Cup brilliant, after scoring duel with classic color everywhere, except eventually enter the semi-finals of the Spanish team are Germany, Portugal, Italy, according to FIFA in June 2012 Ranking first in addition to Italy 12 three other teams ranked outside the top five, the competitive level of football that four national team also represents the highest level in world football $^{[1]}$. The European Football Championship is known as the Football World Cup is known, its ornamental and Athletic inferior to the World Cup, conduct research on the highest level of football competition, countries can learn football situation, a better grasp of world football development trend. Based on the 2012 European Cup semi-finals the team's offensive and defensive relevant statistical indicators and analysis sought to identify good team offensive and defensive characteristics and explore its internal law, for the majority of coaches to guide the training and competition provide a scientific basis .
\end{abstract}

\section{Subjects and Methods}

\subsection{Subjects}

In the 2012 European Cup Final Phase Final Four team carried out 22 games, a total of 40 goals (including the penalty kick showdown match 6 penalty) time Shishe region, into ball player field position, shot mode, the offensive and defensive characteristics of the way as the object of study.

\subsection{Research Methods}

1.2.1 Video clip playback

Of the four teams participating in 22 games live video and goals video playback observation and mathematical statistics. Discussion on four goals and team offensive and defensive characteristics in the game from a statistical analysis of results.

1.2.2 Literature

Now the domestic and foreign relevant papers Soccer Games team offensive and defensive ability to contrast aspects related works, this study provides a theoretical basis and methods.

1.2.3 Mathematical statistics

Data collected corresponding statistical processing using SPSS12.0 for statistical analysis.

1.3 Scale Statistics

Field zoning: Goals video game based on observations and video clips, the scoring area divided into seven regions. Zone 1 is the goal area; 2 area is restricted left side; Zone 3 of penalty area; 4 for 
the restricted area right rib; 5 Road area is outside the area; 6 area is outside the area on the left; 7 area is outside the area on the right. Goals zoning specifically shown in Figure 1. According to the game situation will attack the center and the stadium is divided into two wings, in the middle of the pitch 30m Road, both sides of the wing[2] (Fig. 2).

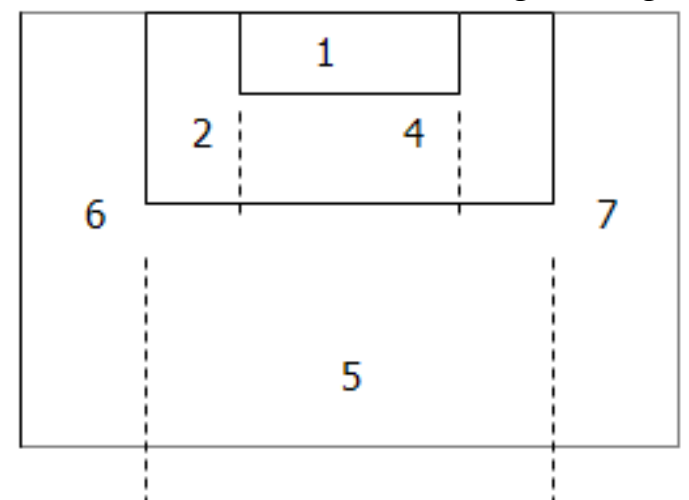

Figure 1 Goals zoning schematic diagram

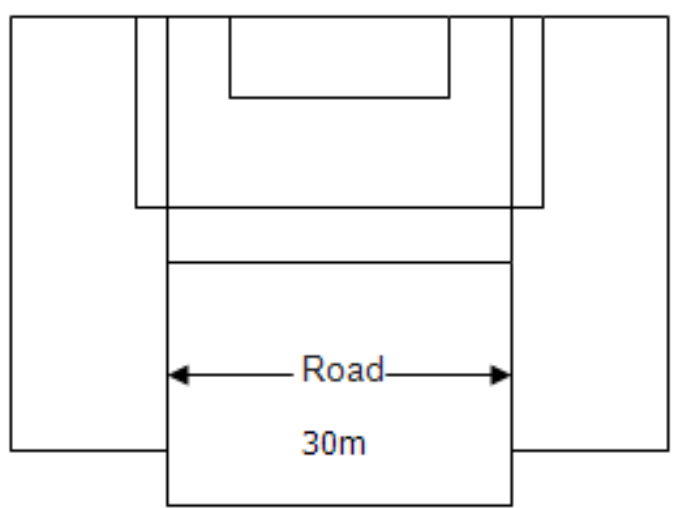

Figure 2 Offensive line schematic division

\section{Results and Analysis}

\subsection{Analysis of four teams pass the ball}

The ability to pass the ball affect the strength of the team to control the degree of competition, according to Table 1, the last four teams in control of the game's performance embodied in the number of passes, the threat of the ball, and Possession several factors , the Spanish team carried out six games, pass the ball 4262 times, averaging 710.3 times, Possession $60.8 \%$, this figure is much higher than the other three teams in the semi-finals, Portugal passing and weak ball, averaging only 378.4 times semifinal between Spain and Portugal for 120 minutes of intense competition, the final penalty kick by Spain 4: 2 victory over Portugal, finals. On the threat to the ball and offside data, Italy total outgoing threats ball 94 times and 16 times total offside while Spain came threat to the ball 81 times and 21 times offside, the two teams showed attacking force and control of the game is relatively strong, but the real threat to the ball game advantage into a winning situation of capacity, compared to the Spanish team returned to Italy to better seize the opportunity to threaten ball advantage into a winning situation.

Table 12012 European Cup semi-finals the team pass the ball Statistics

\begin{tabular}{ccccccccccc}
\hline & & \multicolumn{2}{c}{ Passing } & \multicolumn{2}{c}{ Biography } & \multicolumn{2}{c}{ Threat ball } & Possession & \multicolumn{2}{c}{ Offside } \\
\cline { 2 - 11 } & \multirow{2}{*}{ Event } & $\Sigma$ & $\bar{x}$ & $\Sigma$ & $\bar{x}$ & $\Sigma$ & $\bar{x}$ & $\%$ & $\Sigma$ & $\bar{x}$ \\
\hline Germany & 5 & 2779 & 555.8 & 126 & 25.2 & 63 & 12.6 & 59.8 & 12 & 2.4 \\
Portugal & 5 & 1892 & 378.4 & 126 & 25.2 & 58 & 11.6 & 47.0 & 10 & 2 \\
Italy & 6 & 3013 & 502.2 & 104 & 17.3 & 94 & 15.7 & 51.5 & 16 & 2.7 \\
Spain & 6 & 4262 & 710.3 & 95 & 15.8 & 81 & 13.5 & 60.8 & 21 & 3.5 \\
\hline
\end{tabular}

\subsection{Analysis of four teams shooting goal}

\subsubsection{Goal in the area}

Table 2 shows that four team scores a goal more concentrated in zone 3, which is the middle of the penalty area, pass through, penetrate, break or by positioning the ball crossed the ball to the middle of the penalty area and then follow up by the players to complete the final shot. Video can be seen through the game, the Spanish team often use skilled combination passes and attacking winger shot technology to complete before. While Italy and Germany have external long-range goal, from the sub-show modern football game against the fierce, scraping positive, or use long-range free kick in the attacking position when less than Jiugong directly break, has become a good way, but also fully explain football player on the football field and a football match between spatial 
power of understanding.

Table 22012 European Cup semi-finals team of Scoring Regional statistics

\begin{tabular}{cccccccc}
\hline & 1 Area & 2 Area & 3 Area & 4 Area & 5 Area & 6 Area & 7 Area \\
\hline Germany & 0 & 0 & 8 & 1 & 1 & 0 & 0 \\
Portugal & 1 & 0 & 4 & 1 & 0 & 0 & 0 \\
Italy & 2 & 1 & 1 & 0 & 2 & 0 & 0 \\
Spain & 1 & 0 & 10 & 1 & 0 & 0 & 0 \\
\hline
\end{tabular}

\subsubsection{Goal in time distribution}

According to FIFA Technical statistical methods, the goal time in the game, the second half, each $15 \mathrm{~min}$ as a time period, each game is divided into six time periods ago after statistics[3]. According to the actual situation, will fall into the first half stoppage time of the first $45 \mathrm{~min}$, into second half stoppage time of the first 90min, the second half stoppage time goal is also included in the appropriate time period extra time track the number of small, separate statistics[2]. Goals can be seen from time statistics (see Table 3), the second half of the game more than the number of goals in the first half, the teams showed that after 45 minutes of the game gradually mastered the rhythm of the game and the opponent's offensive and defensive characteristics, in the second half to strengthen the attack. For example, the German team has scored six goals in the second half, the 75-minute period scoring 4 goals, the German team showed a strong willpower to win the offensive. The second half than the first half goals description of each team fierce, often right up to the end of the game will only be a winner. In the final moments bold investment offensive, with the strength to fight opponents, often receive unexpected results, thus rewriting the final score of the game. As it can be seen in modern football game, to compete on the field every minute is crucial, and the end of the game to compete for the more intense phase.

Table 32012 Cup semi-finals of the European Cup Statistics Team Goal

\begin{tabular}{cccccccccc}
\hline & $0-15$ & $16-30$ & $31-45$ & $46-60$ & $61-75$ & $76-90$ & $91-105$ & $106-120$ & Total \\
\hline Germany & 0 & 2 & 2 & 0 & 4 & 2 & 0 & 0 & 10 \\
Portugal & 0 & 2 & 1 & 0 & 1 & 2 & 0 & 0 & 6 \\
Italy & 0 & 1 & 3 & 0 & 1 & 1 & 0 & 0 & 6 \\
Spain & 2 & 1 & 1 & 1 & 2 & 5 & 0 & 0 & 12 \\
\hline
\end{tabular}

2.2.3 Scoring in the way and manner assists

Scoring in the game is to win the ultimate goal of every team, the current European Cup semifinals team shot number and relatively large number of goals. Table 4 shows that four teams a total of 22 games, the CPC launched into 40 goals (including the semi-final between Spain and Portugal 6 penalty), indicating that shooting ability is relatively high, according to the table below shows, the Italian team for six games competition, shot 108 times, averaging 18 times, shot is 61 times, averaging 10.1 times, four teams topped the list, indicating that the Italian team's offensive capability is relatively high, but the total number of goals but only six , ranked last in the four-team, indicating effective, less threatening Shots. Compared to the German team shot, the shot is relatively high and the total number of goals. By way of apparent field goal, the Spanish team to score the highest number of access control, but the German team score, the highest number, also shows the difference between the two teams in the competition field goal on the way, the German team athletic and tough, sharp and Spain exquisite. 
Table 42012 European Cup semi-finals on goal scoring team statistics

\begin{tabular}{|c|c|c|c|c|c|c|c|c|c|}
\hline & \multirow{2}{*}{ Event } & \multicolumn{2}{|c|}{ Shooting } & \multicolumn{2}{|c|}{ On goal } & \multirow{2}{*}{$\begin{array}{c}\text { Total Goals / } \\
\text { Kicks }\end{array}$} & \multicolumn{3}{|c|}{ Shooting scoring } \\
\hline & & $\Sigma$ & $\bar{x}$ & $\Sigma$ & $\bar{x}$ & & Direct & Head & Access control \\
\hline Germany & 5 & 75 & 15 & 41 & 8.2 & $10 / 1$ & 6 & 2 & 2 \\
\hline Portugal & 5 & 80 & 16 & 35 & 7 & $8 / 0+2$ & 2 & 2 & 2 \\
\hline Italy & 6 & 108 & 18 & 61 & 10.1 & $6 / 0$ & 2 & 2 & 2 \\
\hline Spain & 6 & 93 & 15.5 & 58 & 9.6 & $16 / 1+4$ & 1 & 2 & 8 \\
\hline
\end{tabular}

Assists tactical intentions clear, with excellent offensive passing means passing timing right, good placement, so his teammates after the ball does not need to do anything they can score. Assisted technology is built on a solid foundation of basic skills individuals, skilled passing ability, a keen ability to judge the spot, and a tacit understanding with his teammates and the strain on the team skills. On the way to goal assists can be seen (see Table 5), four teams have adopted the direct control of the ball and then pass, but not head the ball, the game has a fast forward control to attack, use the shortest time and least number of passes to create scoring chances[4]. Germany 7 passes directly assists, showed improvements in high-intensity confrontation pass the ball speed, speed up the pace of the game, often resulting in greater pressure will give opponents, and Spain while it was to ensure the success rate of passing through the access control, skilful pass the ball to control the pace of the game and, ultimately, field goal opportunities.

Table 52012 European Cup semi-final team field goal assists Information Statistics

\begin{tabular}{ccccc}
\hline & Direct & Head & Access control & Total \\
\hline Germany & 7 & 0 & 3 & 10 \\
Portugal & 1 & 0 & 5 & 6 \\
Italy & 3 & 0 & 3 & 6 \\
Spain & 2 & 0 & 9 & 12 \\
\hline
\end{tabular}

2.3 Analysis of final Four team offensive ways and means of comparative

Offensive way into a dynamic offensive attack and positioning the ball two kinds. Motion offense in accordance with the field area range is divided into the center and wing in two forms. Attacking is divided into: corner kick, free kick, penalty kick, throw four forms[2]. Table 6 shows, the current European Cup semi-finals in the selection team attack on the way to score more obvious difference, but the teams have stepped up the fight and control of the midfield, the midfield players pass through several local cut with to find neutral, and is poised to form a shot to score. Germany and Spain are often used to complete the final field goal permeate Road; Portugal winger greater emphasis on the use of the manufacturing field goal opportunity, but the Italian team better at using a personal breakthrough and positioning the ball to get a valid field goal, the Italian team total gets 30 corner, a corner and scored two goals. Four teams showed a significant difference in terms of selecting offensive way, Germany and Spain pay more attention to teamwork, to get better scoring chances through the combination passes, which also benefited from strong teams the ability to pass the ball (see Table 1), increased control of the game in order to get better opportunities; and while it was in Portugal to get the chance to score goals by winger tie in pass; Italy, while it was more emphasis on the use of defensive back and positioning the ball Attempt to get scoring opportunities. Seen in the pursuit of simple, quick ways to attack at the same time should pay attention to grasp the rhythm, in the face of intense defensive player capable of rational use of the characteristics of different positions, through reasonable choice opportunity to attack, attack and offensive line mode is particularly important[5]. 
Table 62012 European Cup semi-final field goal team offensive statistics Way

\begin{tabular}{cccccccccccc}
\hline & \multicolumn{3}{c}{ Sidewalk } & \multicolumn{1}{c}{ Road } & \multicolumn{5}{c}{ Positioning } \\
\cline { 2 - 11 } & $\begin{array}{c}\text { Break } \\
\text { through }\end{array}$ & $\begin{array}{c}\text { Penetr } \\
\text {-ation }\end{array}$ & $\begin{array}{c}\text { Biogr } \\
\text {-aphy }\end{array}$ & $\begin{array}{c}\text { Break } \\
\text { through }\end{array}$ & $\begin{array}{c}\text { Penetr } \\
\text {-ation }\end{array}$ & $\begin{array}{c}\text { Long } \\
\text { Passing }\end{array}$ & $\begin{array}{c}\text { Corner } \\
\text { kick }\end{array}$ & $\begin{array}{c}\text { Free } \\
\text { kick }\end{array}$ & Kicks & $\begin{array}{c}\text { Foul } \\
\text { ball }\end{array}$ \\
\hline Germany & 0 & 1 & 2 & 0 & 4 & 0 & 0 & 1 & 1 & 1 \\
Portugal & 0 & 1 & 4 & 0 & 0 & 0 & 1 & 0 & 0 & 0 \\
Italy & 1 & 0 & 1 & 0 & 0 & 1 & 2 & 1 & 0 & 0 \\
Spain & 0 & 1 & 2 & 1 & 6 & 0 & 1 & 0 & $1+4$ & 0 \\
\hline
\end{tabular}

According to Table 7, four team striker is still the team leading scorer, striker attack force directly affect the team's performance, Torres Spain, Germany and Italy Gomez Barlow Terry scored all three goals as the team's top scorer. The main players involved in the avant-garde midfield scheduling, instigated offensive team, but also enhance the ability to score goals. Spain has six goals accomplished by the avant-garde players, we can see a strong team not only in terms of attack power forward needs to have avant-garde offensive score. This is due to the Spanish team to pass the ball control, but also reflects the overall offensive posture. Guard is not only the team's defensive backbone, is the initiator of the attack, to help power through the guard involved in the attack, and then score. Modern football game guard not only bear the team's defensive duties, but also an important weapon to break the team scoring. Linebacker offensive help power plug has gradually become an important means of scoring the team, such as Germany captain Houwei La mother and Spain's Alonso, is the excellent play-back guarantee wit the team win, while but also it reflects the overall modern football offensive posture[6].

Table 72012 European Cup semi-final field goal team player field position statistics

\begin{tabular}{ccccc}
\hline & Forward & Edgy / Midfield & Guard & Total \\
\hline Germany & 6 & 3 & 1 & 10 \\
Portugal & 5 & 0 & 1 & 6 \\
Italy & 5 & 1 & 0 & 6 \\
Spain & 3 & 6 & 3 & 12 \\
\hline
\end{tabular}

2.4 The comparative analysis of the semi-finals team defense

Key to the team victory not only has a strong attack, but also have a solid defense, the development trend of modern football is full power the whole defensive trend. Right on the fast ball attack, the ball would not have become actively defend the basic principles of football offense and defense. According to the statistics need to be a corner, he conceded, steals, fouls, yellow cards and was shot as indicators of the team's defensive ability. Data can be seen by the team defense (see Table 8), the Spanish team had lost only six games 1 goals, averaging 0.17 goals conceded, 121 steals, averaging 20.2 times, he was shot 50 times, averaging 8.3 times, the data shows its defensive strength, which is based on the Spanish team has a good pass the ball technology, the ability to control the game, in addition to 121 times vicious tackling effectively contain the opponent's attack and shot; compared to Germany and after the Italian team in the above comparison of the data at a disadvantage, especially in the final, Spain is in a good solid defense only to fierce attack to 4-0 Italy.

Table 82012 European Cup semi-finals the team defense statistics

\begin{tabular}{|c|c|c|c|c|c|c|c|c|c|c|c|c|c|}
\hline & \multirow{2}{*}{ Event } & \multicolumn{2}{|c|}{ Corner kick } & \multicolumn{2}{|c|}{ Conceded } & \multicolumn{2}{|c|}{ Steals } & \multicolumn{2}{|c|}{ Foul } & \multicolumn{2}{|c|}{ Yellow } & \multicolumn{2}{|c|}{ Was shot } \\
\hline & & $\Sigma$ & $\bar{x}$ & $\Sigma$ & $\bar{x}$ & $\Sigma$ & $\bar{x}$ & $\Sigma$ & $\bar{x}$ & $\Sigma$ & $\bar{x}$ & $\Sigma$ & $\bar{x}$ \\
\hline Germany & 5 & 34 & 6.8 & 6 & 1.2 & 90 & 18 & 49 & 9.8 & 4 & 0.8 & 56 & 11.2 \\
\hline Portugal & 5 & 41 & 8.2 & 4 & 0.8 & 79 & 15.8 & 91 & 18.2 & 12 & 2.4 & 51 & 10.2 \\
\hline Italy & 6 & 30 & 5 & 7 & 1.2 & 96 & 16 & 89 & 14.8 & 16 & 2.7 & 81 & 13.5 \\
\hline Spain & 6 & 43 & 7.2 & 1 & 0.17 & 121 & 20.2 & 81 & 13.5 & 11 & 1.8 & 50 & 8.3 \\
\hline
\end{tabular}




\section{Summary}

3.1 In terms of passing the ball, the Spanish team in terms of the total number of passes, the threat of the ball and dominated possession rate, Germany and Portugal are better at using pass the ball to create scoring opportunities.

3.2 Scoring in context, each team scoring the goal in the penalty area most positive, indicating that this region is also the team principal misses the goal area; shot on goal in terms of time, the number of goals in the second half than the first half number of goals, in particular Germany and Spain in the second half scored significantly higher than the first half; score, and then pass control of the team is still the main means of shooting and assists way forward still scoring main completed, but more guards players are also involved in the attack.

3.3 Ways and means of attack side, the middle penetration and winger still the first choice of the team. In addition, the Italian team often attacked by positioning the ball, and can effectively seize scoring opportunities.

3.4 On defense, after losing possession immediately put into defense, fierce tackling and defensive tactical foul has become the team's overall tactics indispensable aspect.

\section{Acknowlegments}

This work was financially supported "2015 Yulin Municipal Science and Technology Bureau Project(2015CYX_07)”

\section{Reference}

[1] World Sports FIFA rankings [E / B] .http:. //info.sports.sina.com.cn/rank/.

[2] Yang ci yu, Li xian qing, Li qiu liang. Laws of football match goals[J].Cheng du Institute of Physical Education, 2006 (3): 78-81.

[3] Yu ji cheng, Xiao jian yong. Characteristics of space time world cup goals[J]. Chengdu Institute of Physical Education, 2004 (4): 65-67.

[4] Tang jun qiao, Peng wei, Wu hong fei. Modern football tactics and characteristics [J]. Chengdu Institute of Physical Education, 2007, 33 (1): 79-80.

[5] Zhang da wei.The 19th World Football Cup semi-finals team offensive tactics characteristic analysis[J].Physical Education Institute of Shanxi Normal University, 2011,26 (1): 109-111.

[6] Hou Weidong, Yang Dazhi.17th World Cup Goal Statistics and Analysis [J] .

Liaoning Sport Science and Technology, 2003 (2): 36-37. 